\title{
Assessment of the State of Economic Security in Russia Using the Example of the Unemployment Rate Indicator: Fractal Analysis Method
}

\author{
I. I. Belyaev ${ }^{a}$, A. V. Larionov ${ }^{a}$, and S. N. Sil'vestrov ${ }^{a}$ * \\ ${ }^{a}$ Institute for Economic Policy and Economic Security Problems, Financial University under the Government of the Russian \\ Federation, Moscow, 125993 Russia \\ *e-mail: silvestrsn@gmail.com
}

Received October 28, 2020; revised November 2, 2020; accepted November 17, 2020

\begin{abstract}
The article proposes methodological approaches to the verification of indicators of the state of the country's economic security using the method of fractal analysis. Fractal analysis technologies make it possible to determine the nature and dynamics of changes in the indicator, to verify its values (indicative or critical), and also to reveal the rate at which these states are reached on the time horizon of statistical observations. The unemployment rate indicator is selected as an example.
\end{abstract}

Keywords: strategic planning, unemployment rate, fractal analysis, indicators of the state of economic security, indicative and critical values of the indicator of the state of economic security

DOI: $10.1134 / \mathrm{S} 1075700721020027$

Effective activity within the framework of strategic planning involves, in particular, verification of the values of indicators for assessing the level of sustainable socio-economic development of the country and the state of economic (national) security (hereinafter, strategy indicators) [1-3].

For this purpose, in this study, the unemployment rate in Russia is selected. It is one of the most informative assessments of strategizing [4]. The data of the Employment Service on the number of registered unemployed were chosen as the initial data: these data are officially presented by Rosstat, using the concept of "potential labor force" to level the so-called "shadow" employment.

When determining the predicted values of strategizing indicators, various methods are used. Econometric analysis typically involves identifying a dependent variable as well as a set of explanatory variables and meeting a number of requirements for the quality and application of statistics. For example, the conditions of endogeneity in the econometric model of forecasting the unemployment rate, several groups of private explanatory variables are used: indicators of the macroeconomic environment [5], indicators of industry orientation $[6,7]$, indicators of the development of digital technologies $[8,9]$, indicators of personal assessment of workers [10-12], etc. In turn, for predicting demographic indicators, the ARIMA model has demonstrated a high degree of applicability, which takes into account the structural features and patterns laid down in previous periods [13].

Benefits of fractal analysis. One of the possible approaches to verifying the values of a single strategizing indicator can be the method of fractal analysis [14]. The main advantage of fractal analysis in comparison with econometric modeling is the more moderate requirements for the quality of the data used. According to the authors, this method has not yet been used for strategic planning purposes.

The main possibilities of this method [15], which is based on the principle of self-similarity, are:

-Assessing the degree of aggregation of the indicator characterizing the state of economic (national) security.

-Determination of the verified indicative value of the indicator.

-Identification of the critical value of the indicator characterizing the state of economic (national) security.

In addition, fractal analysis allows you to select indicators that have "long memory" (that is, they describe a persistent process), as well as determine the length of the "memory series," which, among other things, contributes to the formation of a rational list of strategizing indicators.

Fractal analysis as a method extrapolation of time series, based on the use of the previous values of the indicator to establish its forecast values, taking into 


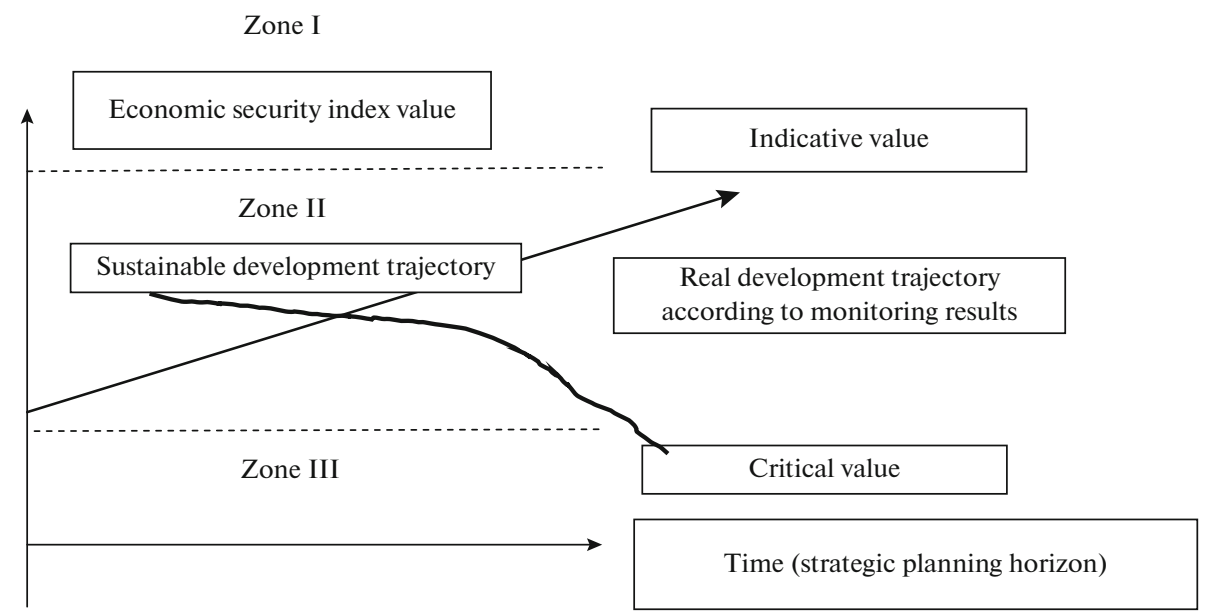

Fig. 1. Generalized view of the life cycle of a single strategy indicator. Source: constructed by authors.

account the fact that the previous structural conditions, institutional mechanisms, as well as parameters of socioeconomic development remain unchanged on the horizon of strategic planning. The logic of fractal analysis suggests that when developing drafts of strategic planning documents, it is necessary to provide for a change in strategic guidelines, the introduction of promising management decisions, due to which the existing structural conditions and parameters of socioeconomic development and strengthening of economic (national) security can be adapted to the requirements of strategic goal-setting. Otherwise, the actual indicative or critical values of the strategizing indicator will be authentic to the values of the previous period, which, in turn, characterizes the insufficient effectiveness of strategic planning. In other words, the method of fractal analysis makes it possible to point out the need to transform the existing structural conditions and parameters of socioeconomic development if strategic goal-setting operates with a more ambitious strategic goal.

In order to clarify the formulation of the problem and understand these capabilities of the fractal analysis method, it is necessary to consider the so-called life cycle of a single strategizing indicator (Fig. 1).

Thus, the indicative value of the strategy indicator is established by the strategic planning document and should be achieved within the framework of the implementation of this document. In turn, the critical value reflects the state of the threat to economic (national) security. It is advisable to consider three main areas in which the calculated indicator can fall:

-Zone $I$, the value of the strategizing indicator corresponds to its indicative value: the strategy achieves its goals.

-Zone II, the value of the strategizing indicator deviates from the indicative value: during the implementation of the strategy, it was not possible to achieve its target purpose; possible strategic risk of disrupting the sustainable socioeconomic development of the country and the emergence of a threat to economic (national) security.

-Zone III, the value of the strategizing indicator does not fully correspond to its indicative value, and reaches a critical level: the direct emergence of a threat to economic (national) security requires urgent implementation of government regulatory measures.

In this case, the possible hit of the indicator value in zone II and especially in zone III should be considered taking into account the rate of change of the statistically observed value of the indicator over time (for example, over a regulated period of statistical observation, or taking into account other requirements for its monitoring). Thus, fractal analysis allows us to determine stable trends in the change in the dynamics of the indicator, as well as to predict its possible critical value in the considered time interval due to the use of the socalled "memory of the series" [16].

The identification of a critical value in a given time interval should serve as a signal for the use of effective government regulation tools [17]. If the actual value of the strategizing indicator is much worse than its critical value, then there is a clear threat to economic (national) security.

Description of data and methods of fractal analysis. (a) Description of statistics. When carrying out fractal analysis, a monthly indicator of the unemployment rate was used: the ratio of the number of unemployed to the number in the labor force [18]. The unemployment rate indicator (Fig. 2) was selected due to the high frequency of its measurement, as well as its importance for strategic planning and management ${ }^{1}$.

\footnotetext{
${ }^{1}$ In particular, section 1.8 "Employment Policy" of the Main Directions of Activity of the Government of the Russian Federation for the period until 2024, approved on September 29, 2018, notes the need to develop mechanisms for protection against unemployment. The creation of an effective employment system was also noted as a priority task in the implementation of the direction for the development of human potential (Decree of the President of the Russian Federation dated May 13, 2017 no. 208 "On the Strategy of Economic Security of the Russian Federation for the Period until 2030”).
} 
The average unemployment rate for the period under review is $7.56 \%$. Taking into account the presence of cyclicality, it can be assumed that the values of this indicator are influenced by the behavioral factors of potential employees, due to seasonal fluctuations in the labor market. To some extent, the reflection of the behavioral factor in this indicator is also associated with the determination of the real number of unemployed, since potential employed are not always inclined to register at the labor exchange as unemployed. The noted features determine the presence of cycles in the dynamics of the unemployment rate, which characterizes the patterns that are amenable to fractal analysis.

(b) Fractal analysis algorithm. To determine the critical level of unemployment, it is proposed to use the so-called $R / S$ analysis ${ }^{2}$.

In this case, the following sequence is realized in general form ${ }^{3}$ :

(1) The original statistics are converted to a logarithmic series:

$$
t_{i}=\ln \frac{x_{i}}{x_{i-1}}, i=2, \ldots \ldots, n+1, \text { where } n+1 \text { is the }
$$

number of observations.

(2) Statistical observations (in this case, 310) are divided into four classes, which include groups with an equal number of consecutive observations $(m)$, i.e., the following breakdown was made: into 31 groups of 10 observations; 10 groups of 31 observations; 5 groups of 62 observations; and 2 groups of 155 observations), where $k$ is the number of groups in each class ${ }^{4}$.

(3) The mean values are found for the logarithmic series of the unemployment rate $t_{a v}=\frac{1}{n} \sum_{i=1} t i$ for all groups in each class.

(4) For each group in each class, the accumulated deviations of the unemployment rate from the average were calculated $X_{i, k}=\sum_{i=1}^{k}\left(t_{j, k}-t_{a v}\right)$ where $t_{j, k}$ are the values of the logarithm of the unemployment rate for $j$ th member of the $k$ th group.

(5) According to the accumulated deviation values for each group $k$, the scope of each class is calculated $R_{k}=\max \left(X_{i, k}\right)-\min \left(X_{i, k}\right)$.

\footnotetext{
${ }^{2}$ The Hurst method is applicable in statistical practice since it is resistant to statistical noise and outliers. The method makes it possible to reveal in statistical data such properties as clustering, a tendency to follow the direction of a trend, a strong consequence, a strong "memory of a statistical series," a rapid intermittency of sequential values, fractality (self-similarity), the presence of periodic and nonperiodic cycles, and a number of others.

${ }^{3}$ The algorithm for performing fractal analysis of time series was compiled on the basis of work [19].

${ }^{4}$ When carrying out fractal analysis, it is advisable to make up groups of 10 observations.
}

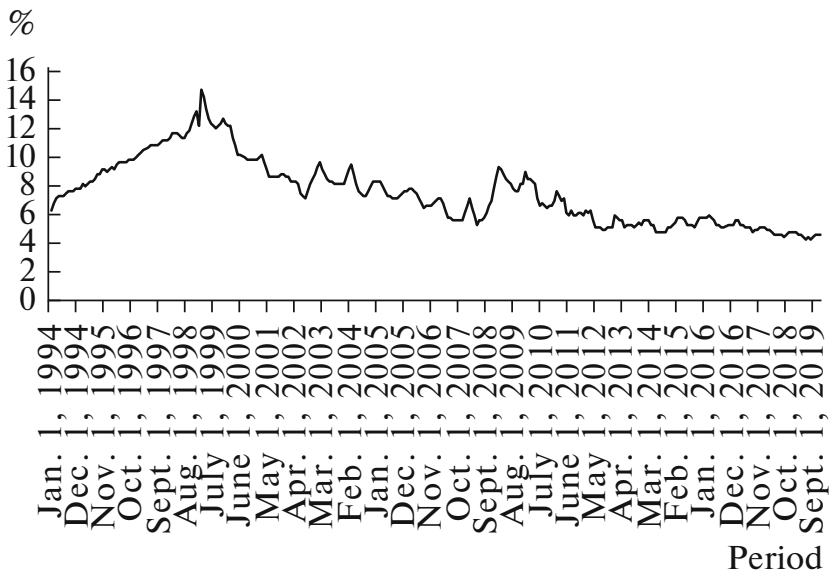

Fig. 2. Dynamics of unemployment rate in Russia. Source: Rosstat data for January 1, 1994-December 11, 2019.

(6) For a logarithmic series (within each group $k$ of each class) the standard deviation is set: $S_{k}=\sqrt{\frac{\sum_{i=1}^{m}\left(t_{j, k}-t_{a v}\right)^{2}}{m-1}}$.

(7) The ratio of the swing to the standard deviation value (normalized swing) is defined as $R / S_{k}=\left(R_{k} / S_{k}\right)$.

(8) The average normalized range is determined $\frac{R}{S(m)}=\frac{\sum_{i}^{k} R / S_{i}}{k}$.

(9) An indicator of the so-called "memory length" of the series is established. The ratio of the average normalized range to the square root of the number of observations in each group of each class: $V(m)=\frac{R / S(m)}{\sqrt{m}}$.

It should be noted that the above calculations (from the third to the ninth sequence) are carried out for all groups of all classes.

The value of the Hurst exponent $(\mathrm{H})$ is obtained from linear regression (least squares method), where $R / S$ is the average value of the normalized range; $\mathrm{H}$, the Hurst exponent; $m$, the number of observations in the group; $c$ is a constant; the number of points in linear regression is equal to the number of classes.

The Hurst exponent $(\mathrm{H})$ takes values from 0 to 1 (Table 1).

Of greatest interest are the data where the Hurst exponent $(\mathrm{H})$ takes values over 0.5 ; i.e., the process has a long series memory, therefore, allows taking into account the structural features of the strategy system.

Calculation of the memory length of the series will allow you to determine the rate of change of the strategy indicator at a specific time interval. Based on the revealed memory length of the series, it is also possible to calculate the critical value of the strategy indicator. 
Table 1. Systematization of possible values of the Hurst exponent $(\mathrm{H})$

\begin{tabular}{l|l}
\hline \multicolumn{1}{c|}{ Possible value } & \multicolumn{1}{c}{ Characteristic } \\
\hline $\mathrm{H}>0.5$ (persistent process) & $\begin{array}{l}\text { The previous values determine the current ones. The series has a "long memory." Such } \\
\text { indicators can be used to assess the state of economic (national) security } \\
\text { There is a constant change in the direction of change in the indicator, and therefore it is } \\
\text { inappropriate to use such types of data to assess the state of economic (national) security. } \\
\text { Data are random }\end{array}$ \\
$\mathrm{H}=0.5$ (antipersistent process)
\end{tabular}

Source: [15].

Table 2. The results of fractal analysis of time series $(R / S$ analysis $)$

\begin{tabular}{l|c|c|c|c}
\multicolumn{1}{c|}{ Parameter } & Class 1 & Class 2 & Class 3 & Class 4 \\
\hline$m$ (number of observations in a group) & 10 & 31 & 62 & 155 \\
$R / S$ (average value of the normalized range) & 3.57 & 5.91 & 9.85 & 19.08 \\
$V$ (process memory indicator) & 1.13 & 1.06 & 1.25 & 1.53 \\
$\operatorname{Ln}(m)$ & 2.30 & 3.43 & 4.13 & 5.04 \\
$\operatorname{Ln}(R / S)$ & 1.2716 & 1.7772 & 2.2879 & 2.9484 \\
\hline
\end{tabular}

Source: authors' calculations.

\section{Results of the performed fractal analyses and their preliminary interpretation}

(a) Determination of Hurst exponent $(H)$ and process memory index. Unemployment rates have been divided into four main classes 5 , then the above transformations are performed. For the corresponding classes, the average value of the normalized range was calculated (Table 2). The break in the value of the "process memory" indicator is observed at the point 1.06 $(n(m)=3.43)$. Thus, the process memory length is about 30 months; i.e., for Russian conditions, the dependence of the unemployment rate on the structural features is typical, typical, as a rule, for the 30 previous months; thus, you can draw a line of the corresponding trend, and the slope of the trend line will show the rate of change of the indicator.

To determine the value of the Hurst exponent $(\mathrm{H})$, a linear regression was built for four classes of observations; the logarithm of the mean value of the normalized range was used as a dependent variable; as an explanatory variable the logarithm of the number of observations in the group was used; the coefficient before the logarithm of the number of observations in the group, the Hurst exponent $(\mathrm{H})$, was 0.615 ; the indicator is significant at the $1 \%$ significance level; $R^{2}$ is 0.98 .

For the Hurst exponent $(\mathrm{H})$ greater than 0.5 , it is fair to conclude that the change in the unemployment rate in Russia is a persistent process. In addition, this unemployment rate is fully aggregated (complex and aggregated, composed of more than one particular indicator) and can be recommended for inclusion in the list of strategizing indicators.

\footnotetext{
${ }^{5}$ The first class included 31 groups of 10 observations; the second class 10 groups, each of which had 31 observations; the third class 5 groups, each consisting of 62 observations; in the fourth grade, all observations were divided into 2 groups of 155 observations, respectively.
}

(b) Establishing the critical value of the indicator. Proceeding from the fact that the change in the unemployment rate is a persistent process (in this case, the memory length of the series is about 30 months), it can be assumed that the previous dynamics of the unemployment rate determine the rate of change in the indicator in the future. Thus, a trend line was constructed (data from 06/01/2017 to 11/01/2019) (Fig. 3, the specified set of values was numbered from 1 to 30 to simplify interpretation). Based on the results obtained, it seems possible to predict the dynamics of changes in the indicator for the next 30 months.

The average rate of change of the indicator on the trend line is $-0.02 \mathrm{pp} / \mathrm{month}$ Thus, the dynamics of changes in the rate of unemployment can be used to assess the state of economic (national) security: if the

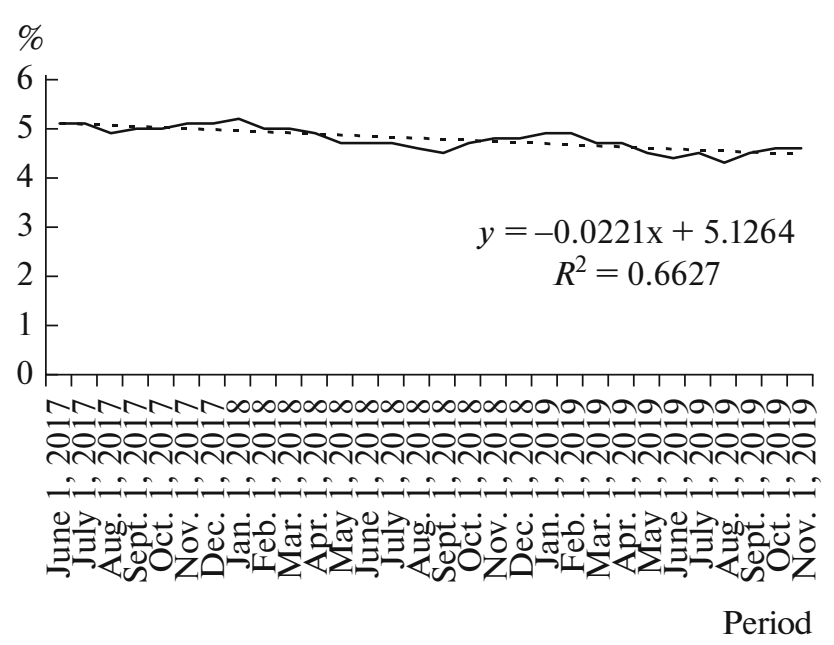

Fig. 3. Trend line (---) for the dynamics of the unemployment rate $(-)$ taking into account the "memory length" of series. Source: authors' calculations. 
Table 3. Assessment of the quality of the unemployment rate forecast based on the results of fractal analysis

\begin{tabular}{l|c|c|c|c}
\hline \multicolumn{1}{c|}{ Date } & $\begin{array}{c}\text { Real } \\
\text { values, } \%\end{array}$ & $\begin{array}{c}\text { Forecast values } \\
\text { (taking into account } \\
\text { memory length series), } \%\end{array}$ & $\begin{array}{c}\text { MAD (Mean } \\
\text { absolute deviation), } \\
\text { percentage points }\end{array}$ & $\begin{array}{c}\text { MAPE } \\
\text { (mean absolute percent } \\
\text { error), \% }\end{array}$ \\
\hline December 1, 2019 & 4.6 & 4.44 & 0.15 & 3.45 \\
January 1, 2020 & 4.6 & 4.41 & 0.18 & 3.93 \\
February 1, 2020 & 4.6 & 4.39 & 0.20 & 4.41 \\
March 1, 2020 & 4.7 & 4.37 & 0.32 & 6.91 \\
April 1, 2020 & 5.8 & 4.35 & 1.44 & 24.95 \\
Average & 4.9 & 4.39 & 0.46 & 8.73 \\
\hline
\end{tabular}

Source: authors' calculations.

actual rate of decline in the rate is less in absolute value (or more in absolute value) than calculated on a linear trend $^{6}$, then we can judge the likelihood of a threat to economic (national) security.

(c) Practical recommendations. Fractal analysis technologies make it possible to verify the values (indicative or critical) of a single strategizing indicator, as well as to reveal the speed of achieving these states in a statistically observed period (provided that the strategic planning paradigm remains unchanged $^{7}$ ). When determining the critical value of a single strategizing indicator, it is advisable to use estimates of the forecast quality, in particular, MAD and MAPE (Table 3$)^{8}$. Thus, MAD demonstrates that the forecast values, on average, deviate by $0.46 \mathrm{pp}$, and the MAPE value is no more than $8.7 \%$, which is a fairly good result. At the same time, the actual trend (increase in the unemployment rate) is opposite to the forecast (decrease). The discrepancies are growing throughout the period under review, which is associated with the significant impact of current negative factors (in particular, the COVID-19 pandemic).

Of course, the influence of environmental factors should not remain out of sight (for example, the dynamics of 2020 are associated with a significant negative impact of the COVID-19 pandemic; there are stochastic fluctuations in the unemployment rate). In order to reduce the unemployment rate, the Government of the Russian Federation has fixed a number of measures to counter the impact of negative trends. In particular, a program has been created to provide preferential loans to employers in order to support employment at $0 \%$. In addition, in relation to small

\footnotetext{
${ }^{6}$ Establishment of the limiting (critical) values of the rate of change of the indicator requires additional expert study.

${ }^{7}$ Revealing the internal relationships between the methodology for determining the critical value of the economic (national) security indicator and the content of the strategic planning paradigm is an independent task outside the scope of this assessment approach.

8 To assess the quality of the forecast, the available statistical values of the unemployment rate were used for the period from January 12, 2019, to April 1, 2020.

9 Decree of the Government of the Russian Federation dated 02.04.2020 No. 422, On Approval of the Rules for the Provision of Subsidies from the Federal Budget to Russian Credit Institutions for the Reimbursement of Lost Income from Loans Issued in 2020 to Legal Entities and Individual Entrepreneurs for Urgent Needs to Support and Maintain Employment.
}

and medium-sized businesses, it was agreed to halve the rates of insurance premiums in excess of payments to employees exceeding the minimum wage ${ }^{10}$ and subsidies provided to maintain employment and pay for their employees ${ }^{11}$. In turn, fractal analysis demonstrates the presence of long-term trends associated with the structure of the economy, which lead to a decrease in the unemployment rate. If the implementation of government support measures will lead to the restoration of the previous trend (taking into account the structure of the economy), it will be possible to speak about the effectiveness of these measures, i.e., on the fulfillment of the conditions for ensuring economic (national) security.

This study offers one of the possible tools for verifying the values of a single strategizing indicator. At the same time, the fractal analysis method (shown by the example of the unemployment rate indicator) fully retains its practical applicability when moving to the assessment of other indicators of the basic list ${ }^{12}$ characterizing the state of economic (national) security ${ }^{13}$.

\section{FUNDING}

The article was prepared based on the results of research carried out by the authors and funded by state order of the

\footnotetext{
${ }^{10}$ Article 6 of the Federal Law of 01.04.2020 No. 102-FZ, On Amendments to Parts One and Two of the Tax Code of the Russian Federation and Certain Legislative Acts of the Russian Federation.

${ }^{11}$ Decree of the Government of the Russian Federation of April 24, 2020 No. 576, On Approval of the Rules for the Provision of Subsidies from the Federal Budget in 2020 to Small and MediumSized Businesses Operating in the Sectors of the Russian Economy that are most affected by the Deterioration of the Situation as a Result of the Spread of a New Coronavirus Infection.

${ }^{12}$ See, for example, the National Security Strategy of the Russian Federation or the Strategy of Economic Security for the Period up to 2030, or the Decree of the President of the Russian Federation of July 21, 2020 No. 474, On the National Development Goals of the Russian Federation for the Period up to 2030.

${ }^{13}$ The elaboration of methods for selecting an indicator (list of indicators) in general for strategic planning remains outside this study. The fractal analysis technology characterizes the mathematical properties of the selected indicator (including the degree of its aggregation), but is not the final method for choosing an indicator (list of indicators) that characterizes the goals of sustainable socioeconomic development of the country and strengthening national security.
} 
Financial University under the Government of the Russian Federation in 2020.

\section{CONFLICT OF INTEREST}

The authors declare that they have no conflicts of interest.

\section{REFERENCES}

1. I. I. Belyaev, "Fundamentals of strategic planning in the field of national security. Comparative analysis: Development of a strategic planning system and its integration into the public administration system," in Proc. Symposium "Problems of Strategic Management," Moscow, April 11, 2019 (Moscow, 2019), pp. 12-18.

2. I. I. Belyaev and A. V. Bulavin, Fundamentals of Strategizing in the Field of National Security. A New Approach to Comparative Analysis (Knorus, Moscow, 2018) [in Russian].

3. Economic Security: Methodology, Strategic Management, and Systems Engineering. Monograph, Ed. by S. N. Sil'vestrov (RUSAINS, Moscow, 2018) [in Russian].

4. V. D. Roik, Social Insurance in the Changing World (Piter, St. Petersburg, 2014) [in Russian].

5. Yu. V. Yaremenko, Theory and Methodology of Researching a Multilevel Economy (Nauka, Moscow, 1999) [in Russian].

6. E. S. Uzyakova, "Labor productivity and economic growth opportunities,” EKO, No. 6, 87-110 (2020).

7. Mei Dong and Sylvia Xiaolin Xiao, "Liquidity, monetary policy, and unemployment," Int. Econ. Rev. 60 (2), pp. 1005-1025 (2019).

8. E. A. Edinak, "Effect of structural changes in unemployment on the dynamics of jobs," EKO, No. 6, 131148 (2020).

9. An Introduction to Online Platforms and Their Role in the Digital Trans-formation (OECD Publ., Paris, 2019). https://www.oecd-ilibrary.org/science-and-technology/an-introduction-to-online-platforms-and-theirrole-in-the-digital-transformation_53e5f593-en.

10. V. N. Bobkov, E. V. Odintsova, and V. V. Kovalenko, "Precarious employment is a global problem of modernity: How can its scale be reduced in Russia?," Stud. Russ. Econ. Dev. 31, 312-317 (2020).

11. V. E. Gimpel'son and A. Yu. Oshchepkov, "Unemployment rate and fear: Are they associated?," Ekon. Zh. Vyssh. Shk. Ekon., No. 3, 277-314 (2011).

12. V. E. Gimpel'son, "Age and wages: Stylized facts and Russian specifics," Ekon. Zh. Vyssh. Shk. Ekon., No. 2, 185-237 (2019).

13. E. D. Kopnova and L. A. Rodionova, "Statistical approaches to the analysis and forecasting of demographic data," Izv. Sarat. Univ., Nov. Ser.: Ekon., Upr., Pravo 16 (3), 306-315 (2016).

14. A. N. Shiryaev, "Foundations of stochastic financial mathematics," in Facts. Models (FAZIS, Moscow, 1998), Vols. 1-2 [in Russian].

15. A. E. Serikov, "Fractal analysis of time series," Sotsiol.: Metodol. Metody Mat. Model. (4M), No. 22, 162-183 (2006).

16. M. P. Afanas'ev and N. N. Shash, "Toolkit for assessing the effectiveness of state programs," Vopr. Gos. Munits. Upr., No. 3, 48-69 (2013).

17. V. N. Yuzhakov and E. I. Dobrolyubova, Methods for Assessing Staffing Needs and Material Incentives for Federal Government Civil Servants, Taking into Account the Introduction of Program-Targeted Methods of Public Administration (RANKhiGS, Moscow, 2016) [in Russian].

18. Urgent Information and Inquiries on Current Issues. Federal State Statistics Service. https://rosstat.gov.ru/.

19. E. V. Pon'kina, Time Series Analysis Methods (Altai. Gos. Univ., Barnaul, 2014), p. 43 [in Russian]. 